\title{
Tension Pneumothorax as a Complication of Colonoscopy
}

We present here a case of tension pneumothorax after routine colonoscopy.

An 80-year-old woman with a history of treated coeliac disease was admitted for investigation of weight loss and diarrhoea. Recent duodenal biopsies were consistent with treated coeliac disease. A chest radiograph (Figure $\mathbf{1}$ ) and subsequent computed tomography of the chest confirmed multiple pulmonary nodules, some calcification and bi-apical scarring consistent with old tuberculosis.

She underwent colonoscopy (receiving pethidine $25 \mathrm{mg}$ and midazolam $3 \mathrm{mg}$ ), which demonstrated severe sigmoid diverticular disease, but due to pain and the severity of the disease, views were only achieved as far as $35 \mathrm{~cm}$. A $2-\mathrm{cm}$ polyp at $20 \mathrm{~cm}$ was removed using a snare and coagulation. The patient complained of severe pain, with abdominal distension. Despite careful withdrawal of the colonoscope with attempted colonic deflation she became hypoxic, cyanosed, and hypotensive. The colonoscopist reversed her sedation, but with no clinical improvement. She was subsequently intubated, but ventilation was difficult, with decreased air entry on the right side. Post-intubation chest radiography revealed a right-sided tension pneumothorax. Free subdiaphragmatic air was not demonstrated. Thoracocentesis and a drainage procedure were performed.

Cases of pneumothorax complicating colonoscopy have been reported previously $[1,2]$. The majority of these appear to be subsequent to colonic perforation after polypectomy, although the anatomic basis for the reported complications varies. Tension pneumothoraces are extremely rare after colonoscopy. A case of tension pneumothorax subsequent to perforation of the transverse colon in a diaphragmatic hernia has been reported [3].

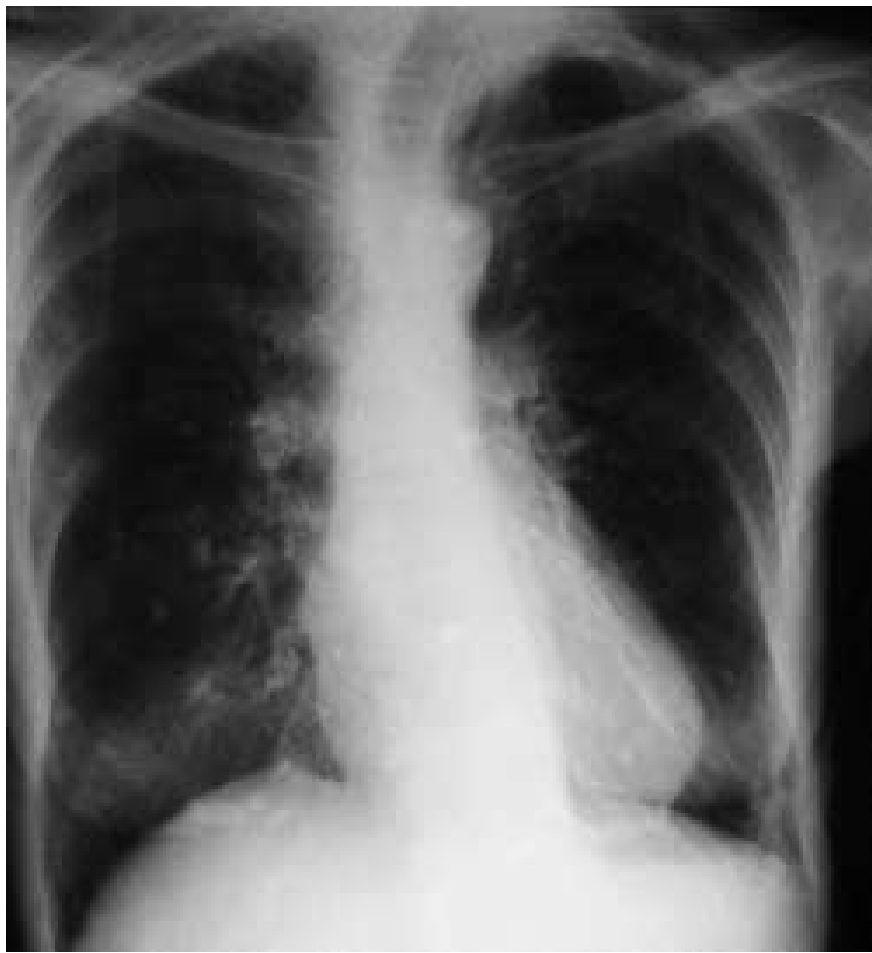

Figure 1 Chest radiograph showing pulmonary nodules, right hilar enlargement, and early apical fibrosis.

In the case presented, it seems likely that the tension pneumothorax arose directly as a result of pulmonary pathology, since no perforation was found at laparotomy. Patients undergoing colonoscopy have increased intrathoracic pressure due to a reflex Valsalva manoeuvre, particularly if the procedure is uncomfortable. In patients who have primary lung pathology, colonoscopists should be aware of tension pneumothorax as a rare complication.

\section{S. A. Hearnshaw ${ }^{1}$, K. Oppong ${ }^{1}$, \\ B. Jaques ${ }^{2}$, N. P. Thompson ${ }^{1}$ \\ ${ }^{1}$ Dept. of Medicine \\ 2 Dept. of Surgery, Freeman Hospital, Newcastle upon Tyne, United Kingdom.}

\section{References}

${ }^{1}$ Webb T. Pneumothorax and pneumomediastinum during colonoscopy. Anaesth Intensive Care 1998; 26: $302-$ 304
${ }^{2}$ Tam WC, Pollard I, Johnson RD. Case report: pneumomediastinum and pneumothorax complicating colonoscopy. J Gastroenterol Hepatol 1996; 11: 789792

${ }^{3}$ Baumann UA, Mettler M. Diagnosis and hazards of unexpected diaphragmatic hernias during colonoscopy: report of two cases. Endoscopy 1999; 31: 274276

\section{Corresponding Author}

\section{S. Hearnshaw, M.D.}

Dept. of Medicine, Freeman Hospital Freeman Road

Newcastle upon Tyne NE7 7DN

United Kingdom

Fax: + 44-191-2231249

E-mail: sarah.hearnshaw@ nuth.northy.nhs.uk 